\title{
Scale Effects on the Melting Behavior of Silver Nanoparticles
}

\author{
M.A. Asoro*, D. Kovar*, J. Damiano**, P.J. Ferreira* \\ *Materials Science and Engineering Program, University of Texas at Austin, Austin, TX 78712, \\ USA. \\ ** Protochips, Inc., 617 Hutton St, Suite 111, Raleigh, NC 27606, USA
}

Nanoparticles possess thermal properties which are different from that of bulk material. Of particular interest is the size-dependent melting point depression observed in nanoparticles. The changes in melting point occur because nanomaterials have a much larger surface to volume ratio than bulk materials. Melting of nanoparticles has been studied by different experimental techniques including electron diffraction [1], x-ray diffraction [2], and calorimetry [3]. However, these techniques are unable to resolve the melting temperature of individual nanoparticles.

To address this issue, we have performed in-situ heating experiments in a JEOL 2010F transmission electron microscope (TEM), to observe in real time, the melting of individual silver nanoparticles with sizes ranging from $5 \mathrm{~nm}$ to $50 \mathrm{~nm}$. Silver was selected for this study due to its resistance to oxidation. We use a novel Protochips Aduro ${ }^{\mathrm{TM}}$ heating stage, which has a microelectro-mechanical-system (MEMS) design and exhibits an extremely low drift even at high temperatures due to its low thermal mass, unlike conventional heating holders. This allows for isothermal experiments to be carried out accurately and precisely in the TEM. The silver nanoparticles were heated in-situ, in increments of $10{ }^{\circ} \mathrm{C}$ from $500{ }^{\circ} \mathrm{C}$ to $720{ }^{\circ} \mathrm{C}$. Later, an isothermal experiment was carried out at $580^{\circ} \mathrm{C}$ on a $15 \mathrm{~nm}$ nanoparticle.

A sequence of TEM images of silver nanoparticles during in-situ TEM heating from $500{ }^{\circ} \mathrm{C}$ to $720{ }^{\circ} \mathrm{C}$ in increments of $10{ }^{\circ} \mathrm{C}$ is shown in Fig. 1. The nanoparticles labeled $\mathrm{A}$ to $\mathrm{K}$ in order of increasing size either vanish from the support or shrink in size before eventually disappearing as the temperature increases. Vapor pressure calculations show that the likely mechanism for the shrinkage and disappearance of the silver nanoparticles observed during in-situ heating is melting followed by vaporization. This mechanism is confirmed by the sequence of TEM images obtained during the isothermal experiment on an individual nanoparticle (Fig. 2). We observe that the shrinkage is inhomogeneous and tends to follow specific planes or surfaces. This is probably due to surface energy anisotropy or interactions between the nanoparticle and the supporting substrate. The melting temperature was recorded at the onset of melting when the particle starts shrinking. Clearly, as the size of the nanoparticles decreases, melting occurs at lower temperatures (Fig. 3). However, we observe significant differences between melting temperatures predicted from theory [4] and our experimentally measured temperatures (Fig. 3).

\section{References}

[1] P. Buffat, J. P. Borel, Physical Review A 13 (1976) 2287.

[2] K. F. Peters, J. B. Cohen, Y.-W. Chung, Physical Review B 57 (1998) 13430.

[3] M. Zhang et al, Physical Review B 62 (2000) 10548.

[4] P. R. Couchman, W. A. Jesser, Nature 269 (1977) 481-483. 


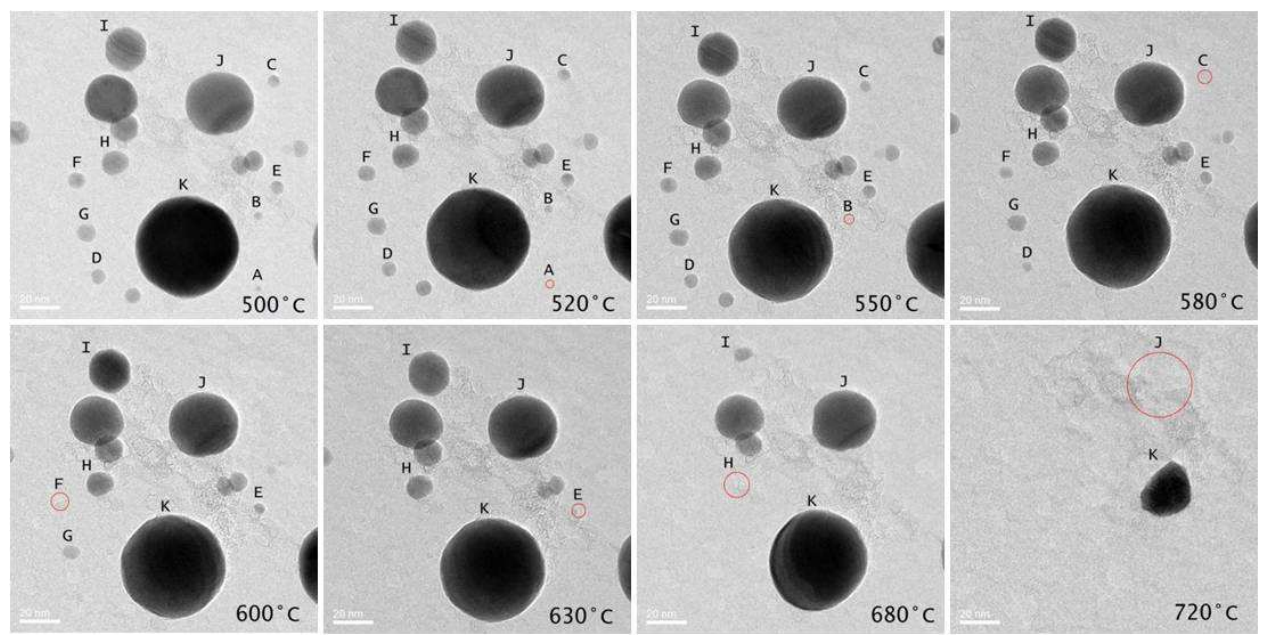

Figure 1: Selected images of silver nanoparticles during in-situ TEM heating at temperatures of $500-720{ }^{\circ} \mathrm{C}$ in increments of $10^{\circ} \mathrm{C}$
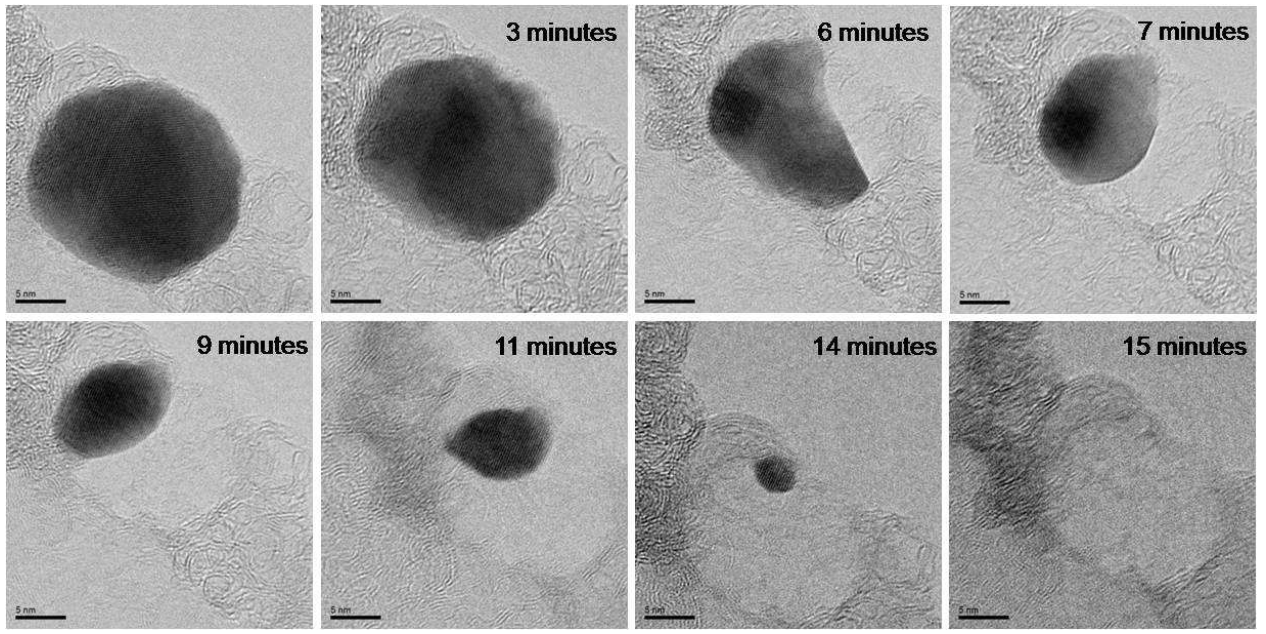

Figure 2: Sequence of TEM images during an isothermal experiment at $580{ }^{\circ} \mathrm{C}$, showing melting and subsequent vaporization of a $15 \mathrm{~nm}$ silver nanoparticle.

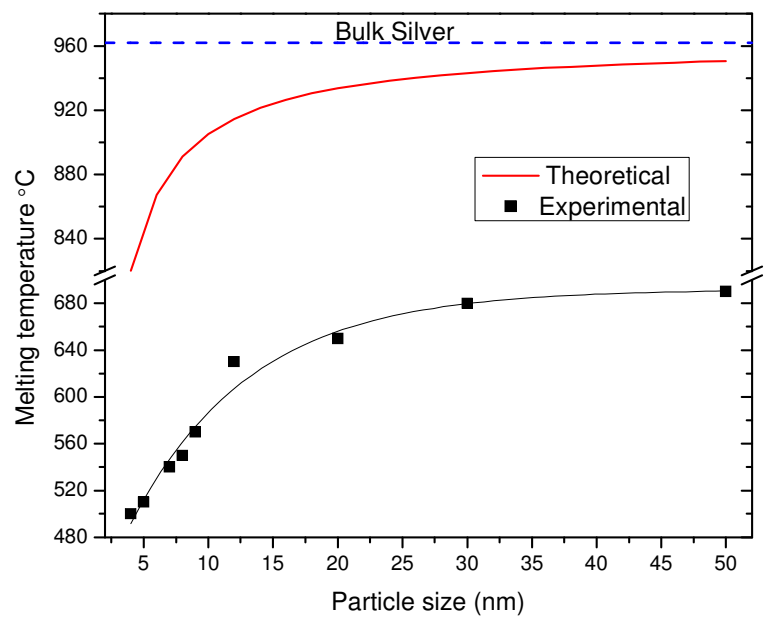

Figure 3: Melting temperature versus nanoparticle size from our experiments and theory. 